\title{
Contextualism and Intellectualism
}

\section{[Conditionally accepted by Philosophical Perspectives]}

Jason Stanley writes:

...contextualists about knowledge ascriptions have discovered many of the examples that suggest that whether a true belief is knowledge depends not just about truth-conducive features of a situation, but on what is practically at stake. However, contextualists generally share the widely held assumption that knowledge is not a matter of practical interests. So they have used these examples, together with the assumption, to argue for the thesis that a predicate such as 'knows that penguins waddle' denotes different knowledge properties on different occasions of use.... (2005: 2-3).

Keith DeRose (2009: 189) concurs but adds that the intellectualist assumption is not only widely held but also seems "exactly right" and the denial of which "seems [to do] considerable violence to the concept of knowledge." DeRose therefore considers the preservation of intellectualism to be a selling point of contextualism against subject-sensitive invariantism. ${ }^{1}$

The main goal of this paper is to show that this common ground between Stanley and DeRose, and which is assumed in the literature generally, is a false assumption. If I am right about this, then one of the main motivations for accepting contextualism over SSI is undermined. This might seem to be good news for SSI. However, other key test cases provide motivations for contextualism, even once intellectualism is abandoned. In fact, I will argue that antiintellectualist contextualism is not merely a coherent possibility but that it has distinct advantages over SSI.

\footnotetext{
${ }^{1}$ Similar claims are made by Stewart Cohen (2004). Cohen identifies an "anti-intellectualist" problem facing John Hawthorne's (2004) SSI which he claims the contextualist avoids (286). See also Schaffer (2006) and Neta (2007).
} 


\section{§1. Contextualism, intellectualism, and a challenge for intellectualism}

I want to begin by explaining how I will understand contextualism and intellectualism. I will then describe the challenge for intellectualism that is posed by certain stakes-shifting cases, as well as the attractive response to it that contextualism provides.

On the sort of contextualism I'll be discussing, laxer and stricter epistemic standards figure in the semantic content of knowledge-attributions in such a way that how strong one's epistemic position with respect to a proposition must be if one is to be truly said to "know" it varies across contexts of attribution. I suspect that my conclusions could be generalized to apply to other sorts of contextualism, but I will not attempt to support this claim. ${ }^{2}$

Next, intellectualism. Stanley characterizes intellectualism in two ways, negatively as the view that "knowledge does not depend on practical facts" (2005: 4) and positively as the view that "only truth-conducive factors are relevant to the question of what makes it the case that someone's true belief is an instance of knowledge" (1). These are not equivalent, as Stanley recognizes. Practical factors are not the only kind of non-truth-conducive factors (there is, e.g., salience of possible error, the day of the week one believes $\mathrm{p}$, etc).

Whichever way intellectualism is characterized, it seems to strike an intuitive chord. If I know that a drug lowers ph level, and you don't, this can't be due to the fact that a lower ph-level would pose no health difficulties for me but would be life-threatening to you (suppose you're taking other medication that would interact disastrously with a lower ph-level but I'm not). If I know and you don't, it must be because I have stronger evidence, better reasons, more reliable or

\footnotetext{
${ }^{2}$ For endorsements of this sort of contextualism, see DeRose $(1992,1995,2009)$ and Cohen $(1988,1999)$, I am thus considering only indexicalist forms of contextualism (see MacFarlane 2007).
} 
safer grounds than you have on the matter. What matters for knowledge are truth-conducive, or more broadly truth-relevant factors, and stakes don't matter because they are not truth-relevant.

I will mostly follow Stanley's positive characterization of intellectualism. Let us think of truth-relevant factors with respect to $\mathrm{p}$ as inducing an ordering on "epistemic positions" with respect to $\mathrm{p}$ : someone might have a stronger or weaker epistemic position with respect to $\mathrm{p}$ than someone else, and I might have a stronger epistemic position with respect to $\mathrm{p}$ at one time and a weaker position at another time.

Equipped with this notion of strength of epistemic position, we can give a reasonably precise explanation of the intuitive notion of being (epistemically) positioned to have a given epistemic status. In general, one is positioned to have status $\Phi$ that $\mathrm{p}$ iff either one $\Phi$-s that $\mathrm{p}$ or, if one doesn't $\Phi$ that $p$, it isn't because one's epistemic position isn't strong enough (or isn't weak enough) to $\Phi$ that p. The advantage of talking about being positioned to have a status one can put aside concerns about the person's doxastic attitudes toward p. Even if one doesn't doubt that $\mathrm{p}$, one's epistemic position with respect to $\mathrm{p}$ can be weak enough for reasonable doubt. Even if one doesn't believe that $\mathrm{p}$, one's epistemic position with respect to $\mathrm{p}$ can be strong enough to know that $\mathrm{p}$.

With all this as background, we can give a uniform characterization of intellectualism about a given epistemic status $\Phi$ as follows:

subjects with equally strong epistemic positions with respect to $\mathrm{p}$ are alike with respect to whether they are positioned to $\Phi$ that $\mathrm{p}^{3}$

\footnotetext{
${ }^{3}$ Even better: if $\mathrm{S} 1$ 's epistemic position with respect to $\mathrm{p}$ is at least as strong as $\mathrm{S} 2$ 's, then if $\mathrm{S} 2$ is positioned to $\Phi$ that $\mathrm{p}$, so is $\mathrm{S} 1$.
} 
Here what substitutes for ' $\Phi$ ' may, but need not, entail belief or some other doxastic status. Thus, we can speak of intellectualism about "ex post" justification - justified doxastic states - as well as "ex ante" justification - being justified to have a doxastic state.

Finally, we can distinguish selective intellectualism about one or more particular epistemic statuses (e.g., knowledge, justified belief) from generalized intellectualism, or intellectualism about all traditional epistemic statuses. Even if it is not clear precisely which statuses comprise the traditional epistemic statuses, we should include among such statuses at least the following: knowledge as well as both "ex post" and "ex ante" justification for doxastic attitudes. Thus, to be a generalized intellectualist - or simply an intellectualist - one must accept intellectualism about knowledge, as well as about justified/reasonable belief, doubt, etc. The distinction between generalized and selective intellectualism will be important in what follows.

Contextualism is a theory about knowledge attributions, rather than a theory of knowledge. However, contextualists typically wish to uphold certain first-order epistemological claims, e.g., that one can know only what is true. Accommodating such claims amounts to taking the corresponding sentences to be invariantly true, true across all contexts of attribution. So, just as to accept the invariant truth of 'only what is true can be known' is to accept the factivity of knowledge under contextualism, so to accept the invariant truth of the formulation of generalized intellectualism is to accept the intellectualist character of knowledge and other traditional epistemic statuses. By accepting first-order epistemological claims, the contextualist places constraints on the epistemic standards semantically associated with knowledge attributions. If 'what is known is true' is invariantly true, then (at least assuming 'true' is invariant) any knowledge-standard must entail truth. If the same holds for 'what is known is believed', then all knowledge-standards entail belief. The same goes for the intellectualist thesis. 
If the contextualist accepts it, she is committed to regarding all knowledge-standards as intellectual, i.e., as not distinguishing (in their application) pairs of subjects who have equally strong epistemic positions.

We now turn to the challenge to intellectualism. The bearing of pragmatic factors on our willingness to claim and deny knowledge of ourselves has been the topic of much recent discussion. The discussion often concerns stakes-shifting cases, a low stakes case (Low) and a high stakes case (High). In High, where the outcomes of your options vary dramatically depending on whether a proposition $\mathrm{p}$ is true, and you're aware of this, you may be more reluctant to say that you "know p" than you would in a low stakes case. Moreover, you might well not merely shrink from claiming that you know in such a high stakes case, but go so far as to say that you don't know. DeRose's (1992) Bank Cases provide the best known example of a Low/High pair. ${ }^{4}$

Such cases pose a challenge to intellectualism. The differing claims made across the cases, at least when considered individually, seem appropriate and true. ${ }^{5}$ But if they are true, this would seem to show that what is good enough for knowledge in Low is not good enough in

\footnotetext{
${ }^{4}$ Bank Case A. My wife and I are driving home on a Friday afternoon. We plan to stop at the bank on the way home to deposit our paychecks. But as we drive past the bank, we notice that the lines inside are very long, as they often are on Friday afternoons. Although we generally like to deposit our paychecks as soon as possible, it is not especially important in this case that they be deposited right away, so I suggest that we drive straight home and deposit our paychecks on Saturday morning. My wife says, 'Maybe the bank won't be open tomorrow. Lots of banks are closed on Saturdays.' I reply, 'No, I know it'll be open. I was just there two weeks ago on Saturday. It's open until noon.'

Bank case B is just like this except for
}

Bank Case B. ...we have just written a very large and important check. If our paychecks are not deposited into our checking account before Monday morning, the important check we wrote will bounce, leaving us in a very bad situation. And, of course, the bank is not open on Sunday. My wife reminds me of these facts. She then says, 'Banks do change their hours. Do you know the bank will be open tomorrow?' Remaining as confident as I was before that the bank will be open then, still, I reply, 'Well, no. I'd better go in and make sure.' (DeRose (1992: 913))

${ }^{5}$ As DeRose (2009: 49-51) claims, no doubt part of the reason they seem true is that they seem appropriate. 
High. After all, the natural conclusion to draw from the fact that "I know the bank is open tomorrow" is true in Bank Case A and "I don't know it is open tomorrow" is true in Case B is that you know in Case A but you don't know in Case B. But then, given the fact that your epistemic position with respect to the bank is open tomorrow is equally strong in the two cases, anti-intellectualism about knowledge would follow. The challenge is therefore to explain why these varying claims seem appropriate and true without abandoning intellectualism. Antiintellectualism, after all, is a hard pill to swallow.

The "classical invariantist" takes a "straight" response to the challenge: despite being appropriate, either your claim to "know" in Low is false or your claim to "not know" in High is false. ${ }^{6}$ This response aims to defuse the threat to intellectualism by rejecting what arguably are the appearances: that you speak truly in both cases.

Contextualism offers a more appealing response. The claims made in the Low/High cases are true and yet intellectualism is also true. Assume you are in High and are thinking about a subject in Low. Assume you can truly deny that you know, and moreover that this isn't merely because you fail to satisfy the belief condition. Assume, that is, that you can truly say 'I don't know' because you can truly say 'I'm not in a position to know'. ${ }^{7}$ Assuming intellectualism about knowledge, it will follow that you can truly deny knowledge of anyone else with an

\footnotetext{
${ }^{6}$ The classical invariantist denies contextualism (as well as assessment relativism) and upholds intellectualism.

${ }^{7}$ Bach (2005: 87) claims that "I don't know" is true in High because belief is absent in High. We could simply replace 'I don't know' in High with 'My evidence isn't good enough to know'. I take it that it is just as plausible to think 'My evidence isn't good enough to know' is true in High as it is to think 'I don't know' is true in High. If you were in High yourself, you would think the main obstacle to your knowing isn't your lack of belief but your lack of strong enough evidence or grounds. You would think, in other words, that you don't know because you're not in a position to know, and not (at least not merely) because you lack belief
} 
epistemic position no better than yours, even if the other person is in a low stakes situation, like Low. The task is then to explain how in High you can truly say 'the guy in Low doesn't know' even though the guy in Low can truly say 'I know'. Here is of course where differences in semantic content come in. In High, the salience of your high stakes drives up the standards for knowing, and so it becomes true to say "I don't know and nor does the guy in Low." In saying this you correctly deny that either you in High or anybody else with your same strength of epistemic position has a very strong epistemic position. But in Low, where no high stakes are salient, in saying 'I know' you affirm about yourself something fully compatible with your lacking a very strong epistemic position, namely that you have a fairly strong epistemic position. Intellectualism is preserved because having a very strong epistemic position and having at least a fairly strong epistemic position are both intellectualist standards.

By adopting this strategy, the contextualist does commit herself to denying intellectualism about the status of being capable of truly self-attributing "knowledge" (the speaker in Low has this status whereas the speaker in High does not). However, if contextualism is true, intellectualism would fail for this status only because non-truth-relevant factors enter into the determination of the content of knowledge-attributions, and not because they enter into the satisfaction of those contents; but it is only if they enter into the latter that a genuine epistemic status is involved. So, generalized intellectualism - the contextualist claims - is preserved.

Thus, we arrive at a fuller statement of the common ground between Stanley and DeRose. Like the classical invariantist but unlike the SSI theorist, the contextualist retains intellectualism. This is a relative advantage of contextualism over SSI. Like the SSI theorist and unlike the classical invariantist, the contextualist accommodates the key intuitions about the truth of what is said in Low and High, namely: 
(Key Intuitions about Low/High)

In Low, you speak truly in saying 'I know p'

In High, you speak truly in saying 'I don't know p'.

This is a relative advantage of contextualism over classical invariantism. One can certainly appreciate the attractions of contextualism if one sees the common ground this way.

A brief outline of what is to come. Crucial to the main argument of the paper is a notion of assertability, epistemic assertability. After clarifying this notion of assertability (\$2), I argue in $\S 3$ that the "key intuitions" about Low and High will be true only if assertability varies across Low and High. In $\S 4$, I argue that if assertability varies across Low and High, then so does believability; and if believability varies, then generalized intellectualism is false. $\S \S 2-4$, if successful, show that the price of accepting the key intuitions about Low and High - with or without the addition of contextualism - is the abandonment of (generalized) intellectualism. Drawing on the relations between believability, justified belief, and knowledge, $§ 5$ extends these conclusions to the case of knowledge. Despite these results, I explore in $\S 6$ some of the advantages of anti-intellectualist contextualism over SSI. I conclude in $\S 7$ by arguing that none of this should be welcomed as good news by classical invariantists.

\section{§2. Assertability}

It is common in philosophy to appeal to what is called "warranted assertability" in order to block inferences from premises about what is appropriate or inappropriate to assert to conclusions about what is true or false. DeRose refers to any such strategy as a WAM, or a warranted assertability maneuver. He discusses a WAM for epistemic possibility claims. It seems inappropriate to assert 'it is possible that p' when you know that p. If I say 'it's possible 
I've been to Orlando', knowing full well that I have been there, then my assertion seems inappropriate. Does this mean we should think that the possibility claim is false when the speaker knows that $\mathrm{p}$ ? No, and we can explain why this by appealing to the conversational maxim "assert the stronger," which applies to a wide variety of claims across subject matters. For instance, when you know p, you shouldn't assert the weaker 'either p or q' rather than 'p', even though 'p or q' clearly is true, and when you know that all Fs are G, you shouldn't assert 'some Fs are Gs', even though this is true. The same principle would bid you to assert 'p', rather than 'it is possible that p' when you know p.

As Adam Leite (2007: 116-7) points out, given the way WAMs work, the notion of appropriate or warranted assertion relevant to WAMs cannot entail truth and the corresponding notion of inappropriate assertion cannot entail falsehood. The whole idea is to block those inferences. Let us call assertability in WAM-relevant sense conversational assertability. ${ }^{8}$ Classical invariantists use a WAM to explain the speaker's statements in High: although in High what is asserted in saying "I don't know" is false, the speaker is conversationally appropriate to assert it (Rysiew (2001), Brown (2006)). In fact, given classical invariantism, it is arguable that the speaker in High knows that what she is saying is false, because she knows that she knows, and so she knows it's false that she doesn't know. ${ }^{9}$ If all this is right, then conversational assertability - WAM assertability - is compatible not just with falsity but with known falsity.

It would therefore be quite wrong to think of the notion of assertability relevant to the "norms of assertion" literature as being conversational assertability (Leite (2007: 117)). If this literature were addressing the latter notion, then all the leading accounts would be dead wrong,

\footnotetext{
${ }^{8}$ Given that the other notion of assertability I will discuss is epistemic, I think the label 'warranted assertability' for the sort of conversational assertability under discussion would be misleading.

${ }^{9}$ Cf. Brown (forthcoming).
} 
because conversational assertability clearly doesn't require knowledge, truth, justification, or belief, and as we've seen is compatible with knowing any and all of these are absent. A much better candidate for being the topic of the norms of assertion literature is the subject's strength of epistemic position with respect to what is asserted. Whereas it might be inappropriate in a general conversational sense to assert 'it's possible that p' when you know that p, your epistemic position with respect to what you assert is clearly strong enough. If you know p, you obviously don't need better evidence, reasons, etc. for it's possible that $p$ to assert it. $\mathrm{P}$ is assertable for you in this sense - epistemically assertable for you - iff asserting $\mathrm{p}$ is proper for you, at least as far as your strength of epistemic position with respect to $\mathrm{p}$ is concerned; that is, you don't need a stronger epistemic position with respect to $\mathrm{p}$ for your assertion that $\mathrm{p}$ to pass epistemic muster. If your assertion is proper in this sense, then your assertion cannot be legitimately criticized (even in a "picky" way) on the grounds that your epistemic position with respect to $\mathrm{p}$ wasn't strong enough.

The two notions of assertability are related, as DeRose (2009: 91n12) persuasively argues. Conversational assertability is a matter of overall satisfaction of conversational maxims, of adherence to something very much like Grice's Cooperative Principle, whereas epistemic assertability is a matter of satisfying a suitable generalization of one such maxim, viz. Grice's second maxim of Quality - 'Do not say that for which you lack adequate evidence'. Because the overall satisfaction of conversational maxims - adherence to a general Cooperative Principle does not entail the satisfaction of each subsidiary maxim (a fact that explains the possibility of conversational implicatures for Grice), conversational assertability does not entail epistemic 
assertability, and of course the converse does not hold either. The notion of assertability we will work with in this paper is epistemic assertability. ${ }^{10}$

\section{§3. The key intuitions about Low/High and variations in assertability.}

To say that (epistemic) assertability is context-variable is to say that it can vary holding fixed the speaker's strength of epistemic position with respect to the proposition in question. Assertability is context-variable, in other words, iff speakers in different contexts differ in whether a proposition $\mathrm{p}$ is assertable for them despite having equally strong epistemic positions with respect to $\mathrm{p}$. To take the most relevant way assertability might vary with context: a speaker in a low stakes case might have an epistemic position strong enough for asserting $\mathrm{p}$, whereas this is not true of a speaker in a high stakes case, despite the fact that the speakers in the two cases have equally strong epistemic positions with respect to $\mathrm{p}$. In this section, I will argue that accepting the key intuitions about Low and High commits one to accepting the contextvariability of assertability.

Although debate rages on about what the norm of assertion is, or whether assertion has any unified norm at all, the following claims about Low and High should be uncontroversial:

(1) In Low, if you can truly describe yourself as knowing $p$, then $p$ is assertable for you.

(2) In High, if $p$ is assertable for you, then you can truly describe yourself as knowing $p .^{11}$

\footnotetext{
${ }^{10}$ If Williamson (2000) is right, epistemic assertability amounts to meeting the condition specified by the unique constitutive rule on assertion. If one thinks of epistemic assertability in this way, one would presumably think of conversational propriety as taking into account both the constitutive rule of assertion as well as rules of a more general nature which are not constitutive of assertion.

${ }^{11}$ To account for the relevance of the doxastic, we should speak here of truly describing yourself as being in a position to know rather than as knowing. I will mostly neglect this distinction. See note 6.
} 
Consider (1). Low is a humdrum situation. The stakes are low not only for you, but for your interlocutor and all relevant third parties. No hard-to-eliminate possibilities of error have been made salient in the conversation. You have not been challenged about $\mathrm{p}$ nor has anyone else in the conversation. You are not speaking to an expert on topics related to . $^{12}$ In short, all the sorts of factors that make philosophers doubt that knowledge suffices for epistemic assertability are absent. In Low, at least, knowledge is warrant enough for assertion. We make this claim acceptable to the contextualist by replacing 'knows' with 'can truly describe yourself as knowing'.

Consider (2). High is a high stakes case in which it matters that one is not sloppy about qualifying one's assertions. The difference between 'p' and 'I think p' or 'very likely, p' makes a real difference, and will be insisted upon in the conversation. In such a context, a flat-out assertion of 'p' might well be challenged with "do you [we] really know that p?", and your interlocutor, upon hearing you assert 'p' flat-out will take you to think you know that p.

\footnotetext{
${ }^{12}$ Nor in Low would you be falsely implying that you had a kind of knowledge that you don't have, as you would if you said to someone curious about a new restaurant "The food there is marvelous" when you had only isolated second-hand knowledge that the food there is marvelous, having never been there yourself and knowing nothing else about the food there (this example comes from Lackey (forthcoming)).

Strictly speaking, however, whether one's knowledge is isolated and/or second-hand is independent of one's strength of epistemic position for the proposition known. I could have a very strong epistemic position with respect to a proposition for which I had only isolated second-hand knowledge (e.g., my knowledge might be based on numerous independent and mutually reinforcing testimonies from known experts). Thus, we cannot show that knowledge isn't sufficient for what we have called epistemic assertability by showing that there are speakers who both know but who are (conversationally) improper to assert what they know due to the fact that they only have isolated second-hand knowledge.
} 
Furthermore, in High, there are no Gettierish misalignments to spoil a connection between having evidence sufficient for knowing and knowing. In short, the sorts of factors that make epistemologists doubt that knowledge is necessary for assertability are absent. In High, one needs at least knowledge for assertability. Perhaps more is required, but less will not do. Again, we recast this in terms of truly describing oneself as knowing.

(1) and (2), when conjoined with the "key intuitions" about Low and High - the intuitions that in Low 'I know' is true while in High 'I don't know' is true - entail that assertability varies across Low and High. Thus, on pain of rejecting the very plausible (1) and (2), which I will assume is a nonstarter, anyone who accepts the key intuitions - contextualist or not - is committed to the claim that assertability varies across Low and High.

\section{§. The implications of variations in assertability for generalized intellectualism}

I doubt most contextualists would be bothered by the conclusion of the previous section. Indeed, in a widely cited paper, DeRose (2002) gives an argument for contextualism based on premises affirming the context-variability of assertability and a contextualized version of the knowledge account of assertion. ${ }^{13}$ This section argues that such variability implies the falsity of intellectualism in its generalized form.

I will argue as follows:

i) If assertability varies across Low and High, so does believability.

\footnotetext{
${ }^{13}$ Reformulated to fit our terminology, this account states that $\mathrm{p}$ is assertable for you in your context iff 'I know that p' is true of you in your context (2009: 99). Notice that this account entails both (1) and (2) but is not entailed by their conjunction.
}

DeRose is not alone among contextualists in endorsing the claim that assertability varies across Low and High. This view is shared by Schaffer (2006) and is sympathetically discussed by Cohen $(2004,486)$. 
ii) If believability varies across Low and High, then generalized intellectualism is false.

So,

iii) If assertability varies across Low and High, then generalized intellectualism is false. If the argument (i) - (iii) is sound, then given the results of $\S 3$, we can conclude that the price of accepting the key intuitions about Low/High - however one packages that acceptance, whether with or without contextualism - is the rejection of generalized intellectualism. If all this is right, then contextualism is not a way of meeting the challenge that Low/High cases pose for intellectualism

§4.1. Defense of Premise (i): If assertability varies across Low and High, so does believability Just as we can speak of epistemic assertability, so we can speak of epistemic believability. $\mathrm{p}$ is (epistemically) believable for you iff believing $\mathrm{p}$ is proper at least as far as your strength of epistemic position with respect to $\mathrm{p}$ is concerned. We should be clear here. Just as in the case of assertion we were speaking of flat-out assertion that $\mathrm{p}$, rather than whatever sort of p-ish assertion is involved in utterances of 'probably p' or 'I think that p' and in making halting utterances of 'p', so here we are speaking of flat-out belief that $p$, rather than whatever sort of $\mathrm{p}$-ish belief is involved in believing that probably $\mathrm{p}$ or in believing that one thinks $\mathrm{p}$ or in merely feeling moderately confident that $\mathrm{p}$. Suppose it becomes apparent in a conversation about exam week that a colleague of yours thinks that it is likely that the last day of final exams is December $17^{\text {th }}$. One way to try to determine whether she also flat-out believes this is to ask her, with the stresses as indicated, "do you believe that the last day of finals $i s$ the $17^{\text {th }}$, or just that it probably is the $17^{\text {th }}$ ?" If she has checked the exam schedule earlier in the day and 
distinctly recalls what she read, then if the context is a normal one, she will say "that it is the $17^{\text {th }}$." If she's relying on a vaguer memory, she will say "only that it probably is the $17^{\text {th }} ., 14$ When my spouse and I have been freely discussing the evidence about whether one of our sons is ill (no fever but unusual tiredness, paleness, loss of appetite), then if I arrive at the flat-out judgment that, yes, he is ill, there will be no gap, consciously at least, between my making this judgment and my asserting flat-out that he is sick. In asserting, I will be making my judgment out loud. And my judgment will be the formation of a flat-out belief that he is ill. Because of these relations between my assertion, my judgment, and my belief, my assertion counts as the expression of my belief. Of course, such relations are not always in place. In many cases, our assertions are carefully planned utterances which may or may not reflect our judgments, and certainly do not have the "feel" of judgments made out loud. (Think about conversations with one's chairperson, one's parents-in-law, or conversations about Aristotle with the resident Aristotle scholar.) In other cases, we judge out loud, but our judgments are not

\footnotetext{
${ }^{14}$ Suppose a student asks you whether you will teach logic next semester. If you say "I probably will teach it," or "most likely, I will," then if the student later in the day is in a casual context, he can report what you said thus: "NN said s/he will teach logic next semester." I won't try to say whether this report would be true or not. But I do think you did not say flat-out that you will teach logic next semester. Notice that if the matter becomes important -suppose the student explains to you later in the day that he is planning to delay taking required courses in order to make room for a logic course with you next semester, thereby risking future scholarship eligibility -- you can remind him, in effect, that you did not flat-out assert you would be teaching logic, by emphasizing that you said only that you probably will be teaching it, not that you will be teaching it. Similarly, in a causal context later in the day, your student later in the day can offer this belief report: "NN believes she will teach logic." Again, I won't try to say whether this belief report is true in that context. The important thing is that you did not have a flat-out belief that you will be teaching logic. Again, if the issue becomes important, you can remind the student that you don't flat-out believe this by emphasizing to him that what you believe is only that you're likely to teach logic not that you will.
} 
formations or manifestations of a belief (e.g., one's judgment might be made in haste, or under the influence of emotion, in which case one might later correctly concede, "I didn't really believe that.”). But much of the time when we make assertions we are expressing our beliefs, or as I will put it in what follows, we are speaking our minds.

In cases in which one is speaking one's mind about whether $\mathrm{p}$, whether one asserts flatout that $\mathrm{p}$ will be determined by whether one believes flat-out that $\mathrm{p}$ : if one has the belief, one will assert; and if one doesn't, one won't. And this is exactly what we find in the sorts of stakesshifting cases that are standardly used to show that assertability is context-variable, i.e., in Low and High.

Imagine you're in DeRose's Bank Case B. You are thinking out loud, speaking your mind, as you often do with your spouse when discussing finances. What you assert will be the direct expression of your belief on the matter. If you hold a flat-out belief that it is open tomorrow, you will express it in a flat-out assertion; if you hold only a qualified belief, you will express this weaker state by asserting the more qualified it is very likely open tomorrow, saying $h \mathrm{~mm}$, or remaining markedly hesitant. I claim in this case that if the bank is open tomorrow isn't assertable then it isn't believable either. What I oppose, then, is the claim that it's not assertable but is believable. In addition to what I think is an intuitive plausibility, I want to give three reasons for thinking that if it's not assertable it's not believable either.

The first is that to think otherwise is to accept the existence of new and peculiar epistemic dilemmas. In Bank Case B, you're speaking your mind. Now suppose it is proper for you to believe the bank is open tomorrow but not to assert it (recall here and throughout we are speaking of epistemic propriety). Then you' re bound to commit an epistemic sin either way: if you escape improper belief by having the flat-out belief, you will end up making an improper 
assertion; if you escape improper assertion by adding a probabilistic qualification or some other hedge, you will have held off on the flat-out belief when it was not proper to do so. We could escape the dilemma, of course, by arguing that you are improper to be speaking your mind. But why would this be? It is not enough simply to say you are proper to believe it flat-out but not proper to assert it flat-out, and therefore you cannot be proper to be speaking your mind. We need an account of why there is something improper about speaking your mind in a situation like this in which most of us would freely speak our minds and in which most of us think this is a situation in which we ought to speak our minds (it's one's spouse!). In the absence of such an account, the assumption that it is proper to be speaking our minds - proper in any appropriate sense, including an epistemic sense - seems plausible.

One might reply that propriety to believe $\mathrm{p}$ doesn't imply impropriety not to believe $\mathrm{p}$, and that therefore the second horn of the dilemma fails. However, unless one thinks that (epistemic) impropriety not to believe something requires absolute epistemic certainty, there will be cases in which a subject lacks absolute epistemic certainty but ought to believe p and so would be improper to withhold belief (we can suppose that in these cases the subject is attending carefully to p). If there are such cases, we can raise the stakes to create a version of High in which the subject is speaking her mind and properly so. To maintain, about such a High case, that $\mathrm{p}$ is believable but not assertable for the subject would commit one to maintaining that the subject (epistemically) ought to believe p but ought not (epistemically) to assert $\mathrm{p}$. This reinstates the epistemic dilemma. ${ }^{15}$

\footnotetext{
${ }^{15}$ My point here is reminiscent of Clifford's (1879) famous remark:

For it is not possible so to sever the belief from the action it suggests as to condemn the one without condemning the other. No man holding a strong belief on one side of a question, or even wishing to hold a
} 
Here is a second reason to think that if the bank is open tomorrow is not assertable in Bank Case B, it is not believable either: a good explanation of its unassertability cites a reason which is also a good reason not to believe this proposition flat-out. Why, in Bank Case B, do you shrink from asserting, flat out, that the bank will be open the next day? You don't weigh the pros and cons of asserting, or engage in any elaborate Gricean reasoning about implicatures to your spouse. Nor does or should it cross your mind that you would be implicating something false about the sort of evidence you have. As DeRose explicitly stipulates concerning Case B, you've told your spouse what your evidence is. Here is a very natural way you might explain why you shouldn't make the flat-out assertion (we can imagine this thinking take place unverbalized):

"I can't assert that the bank is open tomorrow. There is a real risk that it is not open tomorrow. All I can say is that it is very likely open tomorrow."

The explanation you cite for why you shouldn't make the assertion - viz. that there is a real risk that bank isn't open tomorrow - can also be cited as a good reason not to make the corresponding flat-out judgment (to form the flat-out belief). I use the more colloquial term for judgment - 'conclude'. Consider:

"There's a real risk the bank is not open tomorrow. So, I can't conclude that it is open tomorrow, but only that it is very likely open tomorrow."

belief on one side, can investigate it with such fairness and completeness as if he were really in doubt and unbiased...

What Clifford is suggesting about belief and action I am suggesting about flat-out belief and flat-out assertion at least in cases in which it is proper to speak one's mind. 
Difficult questions can be asked about what precisely it is for there to be a "real risk" that something isn't the case. ${ }^{16}$ My point is only that, whatever precisely makes a risk real, a real risk is grounds not only for not flat-out asserting in Bank Case B but also for not flat-out believing either. This is hardly surprising if the flat-out assertion in such a case would amount to the expression of a flat-out belief.

Consider now another way to think about your situation when you're in Bank Case B: "Why can't I assert it? Because there's a real risk it's not true. But that's not a reason to doubt the bank is open tomorrow. I don't doubt it is open tomorrow. It is open tomorrow. The real risk of falsity is a reason not to assert, but not a reason to qualify my belief."

This thinking is problematic, and not only because it relies on the implausible idea that a real risk of falsity is no reason to doubt. It also seems perilously close to a form of Moore's paradox: it's open tomorrow but there's a real risk it's not. This is not merely an instance of 'p but it might not be that p'. The risk is explicitly acknowledged to be a "real" one. So, even if one can say and think coherently something of the form $p$ but there is some chance - a remote and dismissible one - that not-p, it is more doubtful that one can do this when the chance of error the risk - is acknowledged to be "real." 17

A third reason to think that unbelievability and unassertability go together in Bank Case B concerns the relation between quiet speech to oneself and speech aloud to others. ${ }^{18}$ Presumably, if the bank is open tomorrow were believable in this case, then it would be

\footnotetext{
${ }^{16}$ [author's work]

17 [author's work.]

${ }^{18}$ Thanks go to [...] for helpful discussion here.
} 
epistemically proper to judge it to be true, and that if were epistemically proper to judge it to be true, it would also be epistemically proper to assert it quietly to oneself. (If not, this is another, even more disturbing, epistemic dilemma.) But, then, why would it be epistemically improper to assert it loud enough for your spouse to hear? You would not be misleading your spouse about your evidence. You would not be flouting any of the general Gricean maxims, other than the ones concerned directly with having sufficient strength of epistemic position for what one asserts. Your spouse has exactly as much at stake as you do. The danger, it seems, is asserting something flat-out when there is a real risk of error; but again, that same danger applies in the case of assertion to oneself, and to judgment and belief.

So, I conclude that in Bank Case B, and in other appropriate High cases (in which one is properly speaking one's mind), if $\mathrm{p}$ is not assertable, $\mathrm{p}$ is not believable. Given that $\mathrm{p}$ is assertable and believable in Low, it follows that if assertability varies across the cases, then so does believability. In other words, Premise (i) is true.

Some philosophers will question Premise (i) on the grounds that flat-out belief requires little in the way of confidence. Perhaps $51 \%$ confidence will suffice. Such views of flat-out belief are not plausible. Imagine a three-sided coin, if you will, which can hand heads, tails, and $X$. (Think of $X$, perhaps, as landing on its side, and suppose the coin is quite thick.) Imagine it is a fair coin, so that heads, tails, and $\mathrm{X}$ are known to be equally probable outcomes of flipping (as well as the only possible outcomes). If $51 \%$ or even $66 \%$ probability is good enough for epistemically proper belief, then you would be proper to believe flat-out each of the following three propositions: i) heads won't come up; ii) tails won't come up; iii) either heads or tails will come up. That is, you'll be proper to believe flat-out a disjunction of two disjuncts but also proper to believe flat-out the negations of those disjuncts: p or q, yes, but no, p, and no, q! This 
might be acceptable for disjunctions with a very large number of disjuncts, but not when there are only two. It matters of course that we are talking about flat-out belief. I can certainly believe with epistemic propriety that it's likely that heads or tails will come up but also that it is unlikely that heads will come up and that it is unlikely that tails will come up.

Don't we often say "I believe p" when we aren't willing to say simply "p," and wouldn't this be true of you in High as well? If so, doesn't this show that in High one can believe p flatout, refuse to assert $\mathrm{p}$ flat-out, but still be speaking one's mind? It may seem so. But notice that if your spouse persisted: “you believe it is open and not just that it's likely open?" you would have to reply, "just that it's likely open." Compare your reaction if you are questioned about what exactly you believe concerning whether the bank was open two weeks Saturday: "so, do you believe it was open two weeks ago Saturday or just that it probably was?" Here you will say, "that it was open." This suggests that 'believe' when used in these less committal utterances - especially with stress on 'believe' - is not being used for flat-out belief. Something similar can be found with intention. We are often willing to say "I intend to do X" when we are not willing to go as far as to say "I am going to do X." This is not a reason to think that, in cases in which one is speaking one's mind and in which the difference between ' $\mathrm{I}$ am going to $\mathrm{X}$ ' and 'I'm going to try to do X' matters, an assertion of "I am going to do X" wouldn't express flat-out intention, but something weaker. A safer conclusion is that when 'intend' used in such less committal utterances is not being used for flat-out intention. ${ }^{19}$

Finally, an important qualification. I have maintained that in cases in which one is speaking one's mind, a flat-out assertion that $\mathrm{p}$ would express a flat-out belief that $\mathrm{p}$. However, the argument I've given could be modified without loss of plausibility if some other doxastic

\footnotetext{
${ }^{19}$ For more on these less committal uses of ‘believe' see Bach (2008), Moran (2001) and [author's work].
} 
flat-out endorsement of $\mathrm{p}$ were taken to be expressed by the assertion - whether it is judging that p, or being convinced that $p$, or having one's mind made up that $p$, or believing without doubt that $p$, etc. I have assumed and will continue to assume that the attitude is flat-out belief, but all that matters is that it is some doxastic flat-out endorsement of p. $^{20} 21$

\section{§4.2. Defense of Premise (ii): If believability varies across Low and High, generalized intellectualism is false.}

\footnotetext{
${ }^{20}$ It is important for my argument that the relevant doxastic attitude be a flat-out endorsement of p. It cannot merely be a degree of belief with a content p. For I would not argue that one should have a higher degree of belief in Low than in High.

${ }^{21}$ Jessica Brown (forthcoming) argues that contextualists and anti-intellectualists should acknowledge the possibility of cases in which the epistemic propriety of believing $\mathrm{p}$ comes apart from that of asserting $\mathrm{p}$. According to Brown, these theorists themselves rely on the claim that epistemic propriety can be affected by stakes in arguing for their positions. So, for instance, they rely on the claim that in Low one is epistemically proper to act on and assert the relevant proposition, even though in High one isn't. But if stakes can affect epistemic propriety, then presumably if different stakes are associated with belief than with assertion, epistemic propriety of belief and epistemic propriety of assertion will come apart. She suggests, for instance, that these theorists ought to allow that when your stakes are low but your interlocutor's stakes are high that you ought not to assert $\mathrm{p}$ even though it is fine to believe $\mathrm{p}$.
}

I cannot give Brown's arguments the attention they deserve here. I will only make two defensive points. First, my argument in this section does not make fully general claims about whether assertion, belief, action, etc are subject to common epistemic norms. I make claims only about Low and High, and in particular about versions of Low and High - like the Bank Cases - in which the speaker is speaking her mind. Second, because the Low/High cases I consider are cases in which the speaker is speaking her mind, they are ones in which flat-out belief will have flat-out assertion as a consequence, and in which a flat-out assertion will be produced only by a flat-out assertion. So there is no wedge to be driven between the consequences of flat-out belief and flat-out assertion in these cases. 
Recall our understanding of believability: $p$ is believable for you iff believing $p$ is proper at least as far as your strength of epistemic position with respect to $p$ is concerned, iff you don't need a stronger epistemic position with respect to $\mathrm{p}$ for believing $\mathrm{p}$ to pass epistemic muster. This notion was the counterpart to the notion of assertability. One might wonder, though, what believability has to do with the traditional statuses of epistemically justified doxastic attitudes, e.g., justified belief. Strength of epistemic position enfolds many more factors than simply justification, e.g., all factors related to being unGettiered. So, we cannot simply claim that believability amounts to justified belief or being justified to believe.

But while we cannot identify believability with a notion of justified flat-out belief, we can plausibly argue that if believability varies across the Low/High cases it varies because of variations in whether one's epistemic position is strong enough for justified flat-out belief. (I will leave 'flat-out' implied in what follows.) In Low, you are justified in believing that $\mathrm{p}$, and so your epistemic position with respect to $\mathrm{p}$ is strong enough for justified belief. In High, however, if $p$ isn't believable for you, the explanation of why it isn't believable is not that you are in a Gettier situation, nor that $\mathrm{p}$ is false; rather, the explanation would rather be that you aren't justified in flat-out believing $\mathrm{p}-$ you need a stronger justificatory standing with respect to $\mathrm{p}$ (better evidence, more probative grounds, etc). ${ }^{22}$ So, if believability varies across Low and High, so does being justified to believe. But if the latter so varies, holding fixed strength of epistemic position, it follows that there is a traditional epistemic status of which intellectualism is false justified flat-out belief - and therefore that generalized intellectualism is false.

\footnotetext{
${ }^{22}$ Even an externalist about justification can agree to this. An externalist might insist that the quality of the evidence and probative character of the grounds should be understood in terms of suitably externalist notions, such as reliability.
} 
Again, although I have assumed flat-out belief to be the doxastic state that would be expressed by flat-out assertion in cases in which one is speaking one's mind, what is crucial for my argument is only that what would be expressed in these cases is some doxastic flat-out endorsement of $\mathrm{p}$. So, if one insists it is not flat-out belief but rather merely flat-out judgment, the modified conclusion of this section would be that if judgability varies across the cases then generalized intellectualism is false. Whatever we say about belief, I think that if assertability varies between Low and High, intellectualism will be threatened for a number of traditional epistemic statuses other than justified belief, viz. justified judgment, reasonable doubt, and justifiably having one's mind made up. For in High, you shouldn't judge; you should doubt, and you should not be convinced; whereas in Low, it is fine to make the judgment, not to doubt, and to have one's mind made up.

\section{§5. Contextualism and intellectualism about knowledge}

If the conclusions of $\S \S 2-4$ are correct, it follows that any view - such as contextualism as well as SSI - that seeks to accommodate the key intuitions about the stakes-shifting cases must accept the context-variability of assertability and with it the same variability of believability and therefore is committed to denying generalized intellectualism. No such view

can be intellectualist across the board. But the contextualist might hope that she can at least save us from anti-intellectualism about knowledge. What I have called "the key intuitions" explicitly concern knowledge, and not (at least explicitly) justified belief, judgment, doubt, etc. If the contextualist can save these key intuitions while avoiding anti-intellectualism about knowledge, then perhaps that would still be reason to prefer contextualism over its rivals.

Consider the following thesis: 
Equivalence Thesis: You are justified in flat-out believing that $\mathrm{p}$ iff $\mathrm{p}$ is knowledge-level justified for you (that is, iff your justificatory standing with respect to $p$ is strong enough for you to know that $\mathrm{p})^{23}$

To say $\mathrm{p}$ is knowledge-level justified for you, or that your justificatory standing with respect to $\mathrm{p}$ is strong enough for knowledge, is not to imply that you do know, only that you are justified enough to know. You might fail to know because $\mathrm{p}$ is false, or because you don't believe that $\mathrm{p}$, or because, despite your justification, it is too easy for you to believe falsely (e.g., if you're in fake barn country), and so on.

'Justified' can be given either a permissive or an obliging reading. On the permissive reading, the Equivalence Thesis is very solid in the right-to-left direction. If your justificatory standing is strong enough for knowledge, it surely is strong enough for permissible belief. "His evidence is good enough to know but he needs more evidence if he is to permissibly believe" sounds decidedly wrong, even if we bear in mind that we're talking about flat-out belief. Having good enough evidence permissibly to believe seems, if not equivalent to, then weaker than having good enough evidence to know. It is at least arguable that in a lottery case although one's evidence isn't good enough to know one's ticket will lose it is good enough to permissibly believe flat-out it will lose. This is at least a tempting view. But notice how implausible it would be to say that your evidence is good enough for you to know that your ticket will lose but not good enough for you to permissibly believe flat-out that it will lose.

Some externalists will insist that in some cases one needs little or no justificatory standing in order to know but that one needs significant justification to justifiably believe, and that therefore the right-to-left direction of the Equivalence Thesis fails even when 'justified' is

\footnotetext{
${ }^{23}$ See the discussion in [author's work omitted]
} 
given a permissive reading. Chicken-sexers and underconfident test-takers might be wheeled in here. I will not argue against such a view. I need only a weaker claim for my argument: in the Low/High cases like DeRose Bank Cases, in which strength of evidence is crucial to both justified belief and knowledge, justification good enough to know is also justification good enough to permissibly flat-out believe. So, if the subject in High has good enough justification to know, he has good enough justification for permissible flat-out belief.

Here, then, is the problem for contextualists. If they want to keep knowledge intellectual, they will have to say that (3) is true in the speech context of the speaker in Low:

(3) The subject in High knows that $\mathrm{p}$ but ought not to believe that $p .^{24}$ and this seems wrong, because it seems knowledge is enough for permissible belief in High. (3) clashes and is arguably even "abominable" to use DeRose's (1995: 27) favored term, and the fact that it clashes, across contexts, as well as the fact that the negation of the corresponding indicative conditional clashes just as much, is evidence of its invariant falsity. ${ }^{25}$

Suppose that (3) is invariantly false. Then given that 'the subject in High ought not to believe that p' is invariantly true, it follows that 'the subject in High knows that p' is invariantly false. But if that is right, then the contextualist must reject the invariant truth of intellectualism about knowledge. The subject in High is truly describable across all contexts of speech as not

\footnotetext{
${ }^{24}$ To make clear that it is flat-out belief which is at issue, we could consider $(3 *)$, which I take it also clashes:

(3*) The subject in High knows that p but ought not to believe that $\mathrm{p}$, as opposed to believing merely that it is likely that $\mathrm{p}$.

${ }^{25}$ Variations on (3) which replace 'believe' with 'judge', 'be convinced', 'have his mind made up that p' also clash. So, if one insists that if you are speaking your mind in High a flat-out assertion would express rather some doxastic flat-out endorsement other than flat-out belief, there is good reason to think that the arguments of this section could be modified without loss of plausibility to show that intellectualism about knowledge is still sacrificed.
} 
knowing $\mathrm{p}$ while the subject in Low is truly describable in some contexts (including her own) as knowing p. Therefore, there are contexts in which both 'the subject in High doesn't know' and 'the subject in Low knows' are true, even though it's also true in such contexts that the epistemic position with respect to $\mathrm{p}$ of the subject in High is exactly as strong as that of the subject in Low. I conclude that the contextualist cannot save us from anti-intellectualism, even about knowledge. $^{26}$

\section{§6. Whither contextualism?}

If I am right, contextualism does not provide a way for us to accept the key intuitions about Low/High while holding on to intellectualism. Does contextualism have anything to offer us in our attempts to cope with the challenge of explaining the relevance of practical factors to knowledge or knowledge attributions? Or should we simply think of the options as exhausted by SSI and classical invariantism?

I think there is a place for contextualism, anti-intellectualist contextualism. As DeRose (2004) has persuasively argued, and as SSI theorists have themselves recognized, SSI has a difficult time explaining why ordinary speakers in High would deny knowledge to subjects in Low. As DeRose points out, speakers in high stakes cases like High would not say or agree to the statement, "I don't know, but it's likely that the guy over there knows, because he has less at stake." And after a high-stakes speaker in such a case acquires additional and better evidence, enough for her to say "I know" despite the high stakes, she would hardly say or agree to anything like: "Even though I had to get more evidence to know, the low-stakes guy over there knew all

\footnotetext{
${ }^{26}$ The argument of this section resembles John Hawthorne's argument that the contextualist must give up the knowledge norm of assertion (Hawthorne 2004: 85-91).
} 
along." Rather, the speakers in high stakes cases will deny knowledge equally of themselves (before obtaining the additional evidence) and their low stakes counterparts. SSI seems make the wrong predictions on these matters.

SSI therefore has a difficult time explaining third-person knowledge-denials made in high stakes or high standards contexts. ${ }^{27}$ However, contextualism might be usefully combined with anti-intellectualism to avoid such difficulties. One promising way to combine the two views is to propose that when a practical situation demanding a strong epistemic position for relying on $\mathrm{p}$ is salient to speakers in a context $\mathrm{C}$, then 'S knows that p' can be true in $\mathrm{C}$ only if $\mathrm{S}$ has at least as strong an epistemic position with respect to $\mathrm{p}$ as is demanded by the salient practical situation. However, it would still be a necessary condition on the truth of 'S knows that $\mathrm{p}$ ' that $\mathrm{S}$ has an epistemic position sufficient for her own practical situation. This would secure the result SSI had trouble with: it would be false in High for the speaker to say 'I don't know but the subject in Low does'. Similarly, a third-party concerned with the practical situation of High would speak falsely in saying, 'the subject in High doesn't know but the subject in Low does'. ${ }^{28}$

The only misgiving I have about this sort of anti-intellectualist contextualism is that it cannot respect the 'if' direction of the above Equivalence Thesis when 'justified' is given the obliging reading, i.e., when it concerns what one ought to believe. As mentioned above, if epistemic permissibility of belief varies across stakes-shifting cases, so will epistemically required belief. If little is at stake and the situation is normal, not only is it permissible to believe flat-out that the bank is open tomorrow, it is what one ought to believe, and if one is asked about

\footnotetext{
${ }^{27}$ Notice that there is no such problematic data when Low thinks about High. Here the SSI theorist is on more solid ground.

${ }^{28}$ [author's work]
} 
it, and there is no reason not to speak one's mind, this is what one ought to assert. However, if much is at stake, and there is time to perform easy evidence-improving checks, then one ought not to believe flat-out that it is open tomorrow. Suppose, then, that what one ought to believe can vary across suitable Low/High cases. And suppose that the sort of anti-intellectualist contextualism we have been considering is correct. Then following will be true in High:

(4) The subject in Low doesn't have justification good enough to know that p but he ought to flat-out believe $\mathrm{p}$.

This is not as abominable as (3), but it seems problematic nonetheless. If one's justification isn't good enough for knowledge, can't that fact be cited as a legitimate defense for suspending flatout belief on whether p? "Yes, I suspended judgment; I just didn't quite know."

Still, given that (4) is less problematic than (3), and given that SSI has serious troubles with third-person "High-on-Low" knowledge-denials, the prospects for an anti-intellectualist version of contextualism seem relatively bright.

\section{§7. Good news for classical invariantism?}

If my arguments have succeeded, then one cannot accept the key intuitions about the stakes-shifting cases, viz. that "I know" is true in Low and "I don't know" is true in High, without sacrificing intellectualism in general, as well as intellectualism about knowledge in particular. While there might be other reasons to accept contextualism, one of the principal reasons given for accepting it is the prospect of preserving intellectualism while accepting the key intuitions. The classical invariantist might therefore claim that, if the arguments of this paper succeed, both contextualism and SSI are stuck with anti-intellectualism, and only classical invariantism can preserve it. 
The classical invariantist might conclude that classical invariantism gains some confirmation from arguments, but I think this is the wrong lesson to draw. For one thing, as DeRose (2002) notes, the context-variability of assertability has been used by classical invariantists as the basis for an objection to contextualism, the Generality Objection. ${ }^{29}$ It goes like this: the contextualist argues from the context-variability of the assertability of knowledgeattributions to the context-variability of the truth-conditions of knowledge-attributions; however, just about any proposition $\mathrm{p}$ is variable in assertability, and yet we would not want to say that it therefore has different truth-conditions when assertable and when unassertable. For example, 'The bank is open tomorrow' has the same truth-conditions across Bank Cases A and B, even though in A it is assertable and in B it isn't. The objection concludes that, in general, the context-variability of assertability is not good evidence for context-variability in truthconditions, and since the variability of assertability of knowledge-attributions is just an instance of this general phenomenon, such variability is not good evidence for contextualism. Any classical invariantist employing this Generality Objection will have to resist my argument (i) (iii) from $\S 4.1$. Here is why. The premise of the Generality Objection is that assertability varies across contexts for just about any proposition, not just propositions about knowledge. If this premise is true, then surely Low and High provide an example of variable assertability. But the conclusion of my argument (i) - (iii) is precisely that if assertability varies across Low and High, then intellectualism is false. So, any invariantist wielding the Generality Objection will need to deny the soundness of my argument (i) - (iii) on pain of giving up intellectualism.

\footnotetext{
${ }^{29}$ DeRose (2009: 91n11) attributes this objection to Paul Boghossian. DeRose considers this a very tough objection (92) and one which is perhaps driving the sense, among classical invariantists, that the contextualists are making a very basic mistake. But as $[\ldots]$ pointed out to me, it is not easy to find a classical invariantist who defends this sort of objection in print.
} 
Even apart from this tu quoque consideration, which applies at best only to some classical invariantists, the case for the context-variability of assertability is strong. I agree with DeRose:

It is difficult to deny that the matter of how well positioned one must be with respect to a matter to be able to assert it varies with context: What one can flat-out assert in some 'easy' contexts can be put forward in only a hedged manner ('I think...', 'I believe...', 'Probably...', etc.) when more stringent standards hold sway. (2009: 107)

Consider again Bank Case A. Now, while one might have picky objections about this case, if one rejects all strong forms of skepticism, one will have to agree that there are cases like this one in which the person knows but doesn't have absolute epistemic certainty. ${ }^{30}$ Consider such a case, but also one in which the stakes are low for the speaker as well as her interlocutors, and in which all other factors are absent which might arguably spoil the sufficiency of knowledge for assertability. If we put skepticism aside, we will have to agree that the relevant proposition $p$ in this version of Low is epistemically and not merely conversationally assertable for the speaker (here I reaffirm claim (1) from §3). Consider, next, a corresponding High case in which the stakes are raised high enough to make relying on $\mathrm{p}$ as a basis for action too risky, but in which the speaker's epistemic position with respect to $\mathrm{p}$ is exactly as strong as it is in Low. The speaker in this High case is improper to assert $\mathrm{p}-$ at least in the sense that it would not be conversationally appropriate to do so. But it doesn't seem that this failure of conversational

\footnotetext{
${ }^{30}$ As I understand Leite's response to DeRose, he claims that in the low stakes cases, like Bank Case A, the target proposition is not epistemically assertable, though it is assertable in a sense more closely related to conversational assertability. participants in the conversation will let the assertion pass, because it just doesn't matter in the context whether one is fully living up to the strict norm of asserting only what you count as knowing. Such a reply might work for Bank Case A as it is in fact constructed, but I doubt it can work in general, for the reason I give in the body of the text.
} 
assertability is due to anything other than the speaker's failure to meet the conditions imposed by the maxims of assertion that concern strength of epistemic position for what is asserted. It is not as if the assertion of $\mathrm{p}$ would be pointless, irrelevant, disorderly, overly lengthy, nor that it would violate "assert the stronger," nor that it would mislead interlocutors about the kind of evidence the speaker has (again imagine the speaker has summarized her evidence to her interlocutors). The speaker shouldn't assert because her epistemic position isn't high enough. To support this conclusion further, notice that hypothetically bumping up her strength of epistemic position, with suitable changes in the previous conversation (so that she is not being misleading about her evidence), but with no changes in her practical situation, would make the proposition conversationally proper to assert. It looks like what stands in the way of conversationally assertability is precisely the weakness in her epistemic position. ${ }^{31}$

\footnotetext{
${ }^{31}$ As $[\ldots]$ suggested to me, the classical invariantist might reply that the reason the speaker cannot properly assert the relevant proposition $\mathrm{p}$ in High is that she would falsely implicate that her epistemic position for $\mathrm{p}$ was strong enough to act on $\mathrm{p}$. So, $\mathrm{p}$ is epistemically assertable but not conversationally assertable. I cannot give this reply a full treatment here; though see [author's work]. Briefly, though, I think we should ask for an explanation of the postulated implicature. Why is it that in High a flat-out assertion that $\mathrm{p}$ implicates having sufficient epistemic position to act on $\mathrm{p}$ ? Can this implicature be derived from more general conversational principles in Gricean fashion? One thing the classical invariantist should not say is that asserting p implicates sufficient epistemic position to act on $\mathrm{p}$ because it implicates knowledge that $\mathrm{p}$, which suffices for epistemic position sufficient to act on p. If knowledge that $\mathrm{p}$ suffices for epistemic position sufficient to act on $\mathrm{p}$, then assuming knowledge is possible without absolute epistemic certainty, there will be Low/High cases in which the subjects have the same strength of epistemic position with respect to $\mathrm{p}$ but differ in whether they have epistemic position sufficient to act on $\mathrm{p}$, and so differ in whether they know that $\mathrm{p}-$ a consequence amounts to anti-intellectualism about knowledge. A second concern is that to acknowledge that in High p is not conversationally assertable because the speaker's epistemic position isn't strong enough for her to act on $\mathrm{p}$ is arguably to acknowledge that $\mathrm{p}$ is not epistemically assertable: it
} 
So, unless one embraces a strong form of skepticism, one will have a difficult time resisting the conclusion that there are Low/High cases across which assertability varies. Upholding intellectualism is not as easy as one might have thought or hoped.

\section{Works Cited}

- Bach, Kent (2005). “The Emperor's New 'Knows'," in Gerhard Preyer \& Georg Peter (eds.), Contextualism in Philosophy: Knowledge, Meaning, and Truth. Oxford University Press, pp. 51-90.

- Bach, Kent (2008). “Applying Pragmatics to Epistemology,” Philosophical Issues, Volume 18 Issue 1, Pages $68-88$.

- Brown, Jessica (2006). "Contextualism and Warranted Assertibility Manoeuvres," Philosophical Studies 130 (3):407-435.

- Brown, Jessica (forthcoming). "Assertion and practical reasoning: common or divergent epistemic standards?" Philosophy and Phenomenological Research.

- Clifford, William K (1879). “The Ethics of Belief," in his Lectures and Essays.

- Cohen, Stewart (1988). "How to Be a Fallibilist," Philosophical Perspectives 2: 91-123.

- Cohen, Stewart (1999). "Contextualism, Skepticism, and the Structure of Reasons," Noûs, Vol. 33, Supplement: Philosophical Perspectives, 13, Epistemology, pp. 57- 89

- Cohen, Stewart (2004). "Knowledge, Assertion, and Practical Reasoning," Philosophical Issues Vol. 14 Issue 1, p482-491.

looks like the speaker is legitimately criticized for having asserted without sufficiently strong epistemic positionhow strong? Strong enough for actionability. 
- Cohen, Stewart (2005). “Knowledge, Speaker, Subject," Philosophical Quarterly 55 (219): 199-212.

- DeRose, Keith (1992). “Contextualism and Knowledge Attributions," Philosophy and Phenomenological Research, Vol. 52, No. 4, pp. 913-929

- DeRose, Keith (1995). “Solving the Skeptical Problem,” The Philosophical Review, Vol. 104, No. 1, pp. 1-52

- DeRose, Keith (2002). “Assertion, Knowledge and Context,” The Philosophical Review, Vol. 111, No. 2, pp. 167-203.

- DeRose, Keith (2004). “The Problem with Subject-Sensitive Invariantism,” Philosophy and Phenomenological Research 68 (2):346-350.

- DeRose, Keith (2009). The Case for Contextualism. Oxford: Oxford University Press.

- Hawthorne, John (2004). Knowledge and Lotteries. Oxford: Oxford University Press.

- Leite, Adam (2007). 'How to Link Assertion and Knowledge Without Going Contextualist: A Reply to DeRose's "Assertion, Knowledge, and Context".', Philosophical Studies 134 (2).

- MacFarlane, John (2009). “Nonindexical Contextualism," Synthese 166, 2: pp. 231-250.

- Moran, Richard (2001). Authority and Estrangement: An Essay on Self-Knowledge. Cambridge, MA: Harvard University Press.

- Neta, Ram (2007). "Propositional Justification, Evidence, and the Cost of Error.," Philosophical Issues 17 (1):197-216.

- Rysiew, Patrick (2001). "The Context-Sensitivity of Knowledge Attributions," Noûs 35 (4):477-514. 
- Schaffer, Jonathan (2006). “The Irrelevance of the Subject," Philosophical Studies 127 (1):87-107.

- Stanley, Jason (2005). Knowledge and Practical Interests. Oxford: Oxford University Press. 